\title{
'Pra frente, Brasil!' e 'je vous salue, marie': dois casos de censura cinematográfica em tempos de redemocratização (1982 e 1986)
}

\author{
Douglas Reis Priester ${ }^{1}$
}

\begin{abstract}
1.Douglas Reis Priester. Graduado em Publicidade e Propaganda pesquisador de Iniciação Científica financiada pela vice-reitoria de Pós-Graduação e Pesquisa da Universidade Paulista - UNIP. Campus: Cidade Universitária.
\end{abstract}

Bárbara Heller²

Orientadora

2. Barbara Heller. Graduação em Teoria Literátia pela Universidade Estadual de Campinas (1982), mestrado em Ciências da Comunicação pela Universidade de São Paulo (1990) e doutorado em Teoria Literária pela Universidade Estadual de Campinas (1997) e pós-doutorado em Comunicação pela Universidade Metodista (2011), sob a supervisão do Prof. Dr. Laan Mendes de Barros. Atualmente é docente do Mestrado e do Doutorado em Comunicação da Universidade Paulista (Unip), parecerista ad hoc da Fapesp. É membro do Observatório em Comunicação, Liberdade de Expressão e Censura (Obcom) da ECA-Usp e é pósdoutoranda, também na ECA-Usp, sob a supervisão da Profa. Dra. Maria Cristina Castilho Costa. Leciona no curso de Letras, nível graduação, no Centro Universitário Fundação Santo André. Tem experiência na área de comunicação e literatura, com ênfase nos seguintes temas: estudos de gênero, estudos culturais, leitura, mídia impressa e identidade.

\section{Resumo}

A pesquisa intitulada 'Pra frente, Brasil! e Je vous salue, Marie; dois casos de censura cinematográfica em tempos de redemocratização (1982 e 1986)' tem por objetivo investigar as maneiras pelas quais os censores continuaram exercendo seu poder, embora o Brasil já estivesse passando pelo período reconhecido como "redemocratização", a partir da eleição, ainda que indireta, de Tancredo Neves à presidência. Os dois filmes são emblemáticos da manutenção de uma cultura censória e serão analisados tanto seus conteúdos, como a documentação existente no site http://www.memoriacinebr.com.br/ do filme Pra frente, Brasil! e textos acadêmicos voltados à censura no período pré e pós golpe militar de 1964.

Palavras Chave: censura, golpe militar, redemocratização, Brasil 1964

\section{Abstract}

The research entitled 'Pra frente, Brasil! and Je vous salue, Marie; two cases of film censorship in times of redemocratization (1982 and 1986)' aims to investigate the ways in which the censors continued to exercise its

\footnotetext{
1 Pesquisa de Iniciação Científica financiada pela vice-reitoria de Pós-Graduação e Pesquisa da Universidade Paulista - UNIP. Campus: Cidade Universitária. Curso: Publicidade e Propaganda. Orientado pela Profa. Dra. Bárbara Heller
} 
power, although Brazil was already going through the period known as "redemocratization", from the election, even indirect, of Tancredo Neves for the presidential post. Both films are emblematic of the maintenance process of censorial culture and will be analyzed by their contents, such as the existing documentation in http:/ / wnw.memoriacinebr.com.br/ website for 'Pra frente, Brasil!' and academic texts aimed at censorship in the pre and post 1964 military coup.

Keywords: censorship; military coup; redemocratization; Brazil 1964

\section{Introdução}

A investigação cumpre o roteiro: introdução, metodologia, resultados, discussão e considerações finais da compreensão dos fatos investigados, que retratam um momento brasileiro de censura.

Por censura, Aurélio esclarece como: algo que se pode definir "exame crítico de obras literárias ou artísticas" (Dicionário Aurélio Online, 2011).

O presente projeto destaca o fato de que censurar seja mais que examinar criticamente uma obra: é proibir uma publicação ou encenação por inteiro ou por partes, procedimento que causa a destruição de filmes ou de qualquer outro tipo de expressão. No caso dos filmes, devido aos cortes que eram feitos, tirando muitas cenas que eram de grande importância, tornavam o entendimento da obra praticamente impossível, como foi o caso de "Je Vous Salue, Marie" (Godard, 1985). O filme tornou-se quase incompreensível devido à censura, tornando seu entendimento capaz apenas pela referência da história de Maria, que é de conhecimento popular e universal. Além desse filme, este projeto analisa, ainda, "Pra frente, Brasil" (Farias, 1982).

$\mathrm{O}$ ato de censurar vem de longa data. Há que constam a lista de obras que, por ter conteúdo iluminista, que criticasse a igreja ou a monarquia, eram proibidos em Portugal e em suas colônias desde o século XVI.

Há também exemplos bem mais recentes, como "O bandido da luz vermelha", de Rogério Sganzerla, "Macunaíma", de Joaquim Pedro de Andrade, ou até mesmo "Rio, 40 graus", de Nelson Pereira dos Santos, que teve sua exibição proibida mesmo após sua estreia, em 1955, justificada assim pelo censor e chefe de polícia da época:, "a média da temperatura do Rio nunca passou dos $39,6^{\circ} \mathrm{C} "$.

[In:http://jornalismoculturalfacamp11.blogs pot.com/2011/ 05/ resenha-rio-40graus.html. Acesso em 25/04/2011].

Com o golpe militar de 31 de março 
de 1964, que afastou o Presidente da Republica João Goulart dando lugar ao Marechal Castelo Branco, instalou-se a ditadura militar no país, que durou até 1985 com a eleição de Tancredo Neves. Com o regime militar em vigor, houve a publicação do Ato institucional número 5, ou AI-5, e o fechamento do Congresso Nacional, em dezembro de 1968. A partir de então, a censura se tornou algo explícito, prévio e obrigatório.

Os filmes analisados datam, respectivamente, de 1985 e 1982, sendo o primeiro de produção franco-suíça e, o segundo, brasileira. Nesse contexto, notamse que as análises demandam o exame dos fatores de censura já no processo de abertura política. Assim, pergunta-se: Que fatores prevalecem no contexto sóciopolítico do Brasil que resultaria na censura persistente de algumas obras artísticas, como essas cinematográficas?

A censura, no Brasil e em todos os países se apresenta como um instrumento de controle social muito eficaz, fato que o regime militar se aproveitou bastante causando, assim, a tão discutida repressão política, que dava margem às práticas violentas como: torturas, espancamentos, penas de morte, perseguições, discriminação, exílios e entre outros métodos de repressão.

A proibição de filmes durante $\mathrm{O}$ regime militar havia sido muito comum, devido à falta de quesitos nas avaliações, tornando a censura quase um ato de livre arbítrio dos censores, como o caso de "Rio, 40 graus", citado anteriormente. Segundo Flaubert (1821-1880), "a censura, seja qual for, parece-me uma monstruosidade, algo pior que o homicídio; $\mathrm{O}$ atentado contra o pensamento é um crime de lesa-alma." [In: http://jus.uol.com.br/revista/texto/ 11630/a-inconstitucionalidade-do-novoartigo-478-do-cpp. Acesso: 23/04/2011]. Com a censura, o espectador é obrigado a formular uma falsa imagem do assunto em pauta, uma imagem pronta e manipulada. É um instrumento voltado para ratificar e fortalecer os interesses do grupo detentor do poder de estado naquele momento, tornando praticamente impossível a formulação de ideias novas, ou fora dos objetivos de quem está no poder. Os censores queriam manter a hegemonia ideológica da sociedade, diziam que com a censura estavam poupando a sociedade de idéias ou opiniões que os afetariam.

Nessa primeira análise, fica evidente que não podemos nos deixar enganar, pensando que a censura seja coisa do passado pois, até hoje, ela exerce efeito nas decisões políticas e sociais, só que não é mais algo explícito e nem obrigatório. Porém, como a ênfase dessa pesquisa, como indicado em seu título, é na censura dos filmes "Pra frente Brasil" e "Je vous salue, Marie", que vamos nos ater ao período chamado de "redemocratização" 


\section{Método}

Trata-se de uma análise documental e de conteúdo dos filmes "Je vous salue, Marie" (Godard, 1985) e "Pra frente, Brasil" (Faria, 1982), seguindo as seguintes etapas:

1. Assistir aos filmes citados;

2. Análise dos filmes e dos trechos que, reconhecidamente, os condenaram à censura;

3. Análise das mediações do diretor e da censura em "Pra frente, Brasil" e "Je Vous Salue, Marie";
4. Leitura de textos acadêmicos sobre censura;

5. Análise geral dos resultados;

6. Redação do relatório.

Um dos locus possíveis para pesquisa é a Pinacoteca do Estado de São Paulo, pois grande parte do edifício deu espaço para o Departamento Estadual de Ordem Política e Social (DEOPS/SP), o famigerado "DOPS", no período de 1940 a 1983. Porém, hoje é um museu dedicado à preservação das memórias da repressão e da resistência política.

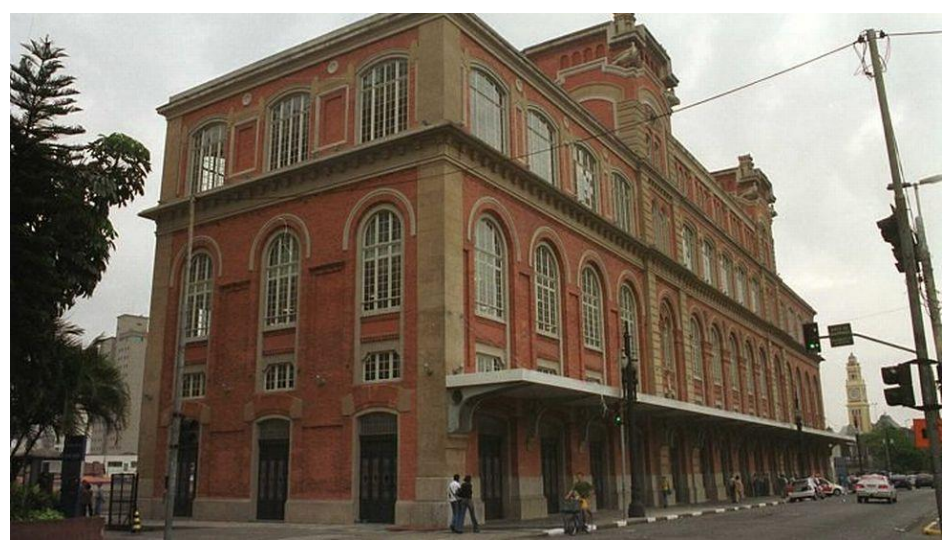

http://extra.globo.com/noticias/brasil/763661-28b-

81d/w976h550/03 02 ghg sp museu12.jpg

Outra importante fonte já utilizada na pesquisa é o site www.memoriacinebr.com.br, Memória da Censura no Cinema Brasileiro: 1964 - 1988. No site, é possível encontrar documentos, processos e arquivos de imprensa sobre 444 filmes que foram produzidos nesse período. Nessa documentação, é possível ver os procedimentos que eram realizados e os problemas que os diretores e as produtoras enfrentavam, podendo partir de palavrões censurados até interdição total dos filmes. 


\section{Resultados}

\begin{tabular}{|c|c|c|}
\hline Título & $\begin{array}{l}\text { Je Vous Salue, Marie (França, Jean-Luc } \\
\text { Godard, 1985). }\end{array}$ & Pra frente, Brasil. (Brasil, Roberto Farias, 1982). \\
\hline $\begin{array}{l}\text { Protagonistas } \\
\text { Principais }\end{array}$ & $\begin{array}{l}\text { Marie: Estudante, trabalha no posto de } \\
\text { gasolina do pai e joga basquete. Joseph: } \\
\text { Taxista e noivo de Marie. } \\
\text { Anjo Gabriel: Anjo que dá a mensagem a } \\
\text { Maria. } \\
\text { Eva: Aluna que tem relações com o } \\
\text { professor. }\end{array}$ & $\begin{array}{l}\text { Jofre: É um cidadão comum, sem qualquer } \\
\text { ligação com a política ou grupos subversivos. } \\
\text { Miguel: Envolvido com uma milícia e irmão de } \\
\text { Jofre. } \\
\text { Mariana: Mulher de Jofre. } \\
\text { Dr Barreto: Chefe de uma milícia clandestina. }\end{array}$ \\
\hline $\begin{array}{l}\text { Contexto } \\
\text { Histórico }\end{array}$ & $\begin{array}{l}1980 \text { marcou a França por violência, } \\
\text { lutas armadas de extrema esquerda, } \\
\text { terrorismo de extrema direita e aumento } \\
\text { da repressão nos estados democráticos. }\end{array}$ & $\begin{array}{l}\text { 1980. O Brasil já estava no final dos anos de } \\
\text { chumbo. Com a eleição de Tancredo em } 1985 \text { e a } \\
\text { nova constituição de } 1988 \text {, era um período que a } \\
\text { censura estava mais maleável, porém ainda } \\
\text { existente. }\end{array}$ \\
\hline Cenários & $\begin{array}{l}\text { O filme tem poucos cenários marcantes, } \\
\text { como: Posto de Gasolina onde Marie } \\
\text { trabalhava. }\end{array}$ & $\begin{array}{l}\text { O filme tem uma série de cenários. Táxis, } \\
\text { apartamentos, delegacias, a casa em que ocorre o } \\
\text { tiroteio, a fazenda onde fica o cativeiro de Jofre. }\end{array}$ \\
\hline Enredo & $\begin{array}{l}\text { Marie trabalha no posto de gasolina do } \\
\text { pai, e um dia Joseph, seu noivo e taxista, } \\
\text { chega com um homem e uma menina, } \\
\text { depois identificados como Anjo Gabriel } \\
\text { e sua acompanhante. Gabriel diz a Marie } \\
\text { que ela terá um filho, e tenta explicar a } \\
\text { seu noivo o que está acontecendo. Ele } \\
\text { desacredita, pois nunca tocara em Marie. } \\
\text { Já ela não sabe como pode ter um filho } \\
\text { mesmo sendo virgem, então vai ao } \\
\text { medico e ele também não entende, mas } \\
\text { confirma o fato. }\end{array}$ & $\begin{array}{l}\text { Jofre é sequestrado ao aceitar carona de um } \\
\text { desconhecido. O carro é atacado por um grupo de } \\
\text { estranhos, que matam o motorista e o estranho } \\
\text { durante a trajetória. Jofre é torturado com a } \\
\text { alegação que ele tenha ligação com organizações } \\
\text { subversivas. Miguel, irmão de Jofre, e sua } \\
\text { cunhada passam a procurá-lo desesperadamente, } \\
\text { sendo envolvidos, casualmente, em atividades } \\
\text { com grupos de direita e terroristas de esquerda. }\end{array}$ \\
\hline Desfecho & $\begin{array}{l}\text { O menino nasce e segue seu caminho. } \\
\text { Maria vai viver sua vida e realizar os } \\
\text { desejos que há algum tempo vinha } \\
\text { reprimindo. }\end{array}$ & $\begin{array}{l}\text { Jofre é morto durante as torturas, sua mulher e } \\
\text { filha viajam em busca de refúgio no exterior. } \\
\text { Dr. Barreto é morto em tiroteio. }\end{array}$ \\
\hline
\end{tabular}

\section{Discussão}

A censura é um homicídio à arte, uma prisão, um desacato à criatividade. Então, por que censurar? Por que proibir o resultado de um dom que nos foi concedido?
A repressão política é um fator que muito nos prejudicou no decorrer dos anos, porque muitas epifanias artísticas foram proibidas, e a arte, a criação dependem muito do repertório de idéias já concebidas, como dizia Lavoisier (1743-1794): "nada se cria, nada se perde, tudo se transforma". 
Por que reprimir os artistas, ou pior, por que proibir a arte? A arte é feita para ser mostrada, para ser discutida, assistida, estudada, apreciada e, principalmente, compartilhada. O artista faz sua arte para que suas ideias, ali retratadas, se ampliem, criem vida e ensinem um pouco à humanidade. Mas, talvez, esse seja o ponto, por que ensinar à população? Para que fazêla pensar? Por que dar-lhes esse direito? É mais prático e, convenhamos, fácil dar uma ideia pronta, mostrar algo já programado, tornando assim a população uma grande massa de manobra, que não sabe pensar, não sabe digerir as informações (e nem precisa), de tanta coisa pronta que chega o tempo "domesticada" que não voltará a mostrar suas garras de novo. Teoricamente.Censurar tem como objetivo reprimir os pensamentos alternativos, subversivos ou não, tudo a fim de manter o status quo e, consequentemente, a vontade de mudança, assim evitando certos conflitos e discussões.

\footnotetext{
"a censura não pode ser conceituada como um fenômeno isolado, atípico, ocasional [...] A censura e a violência física e simbólica, a coação moral, são elementos que não integraram somente o projeto politico do regime militar pós-64, mas fizeram parte de diversos governos, em diferentes momentos da bistória brasileira." [STEPHANOU, Alexandre Ayub].
} inteiro. Assim, é criada uma população

Mas não podemos nos enganar pensando que a censura não está mais presente na nossa sociedade atual, não podemos pensar que só porque com a promulgação da Constituição de 1988, que extinguiu a censura, os serviços de Censura de Diversões Públicas nos estados e na União, além do Departamento de Ordem Política e Social (DEOPS), estamos livres dos censores. Na sociedade atual é possível encontrar indícios de censura, menos explícitos, porém ativos. A censura moderna é feita através dos meios de comunicação. Alguns exemplos como os seguintes podem ser vistos nos dias de hoje.

1 [...] na campanha eleitoral um tribunal de Tocantins proibiu 84 meios de comunicação de tornar pública uma investigação criminal sobre o governador Carlos Gaguim (PMDB), candidato à reeleição que acabou derrotado. Em outra instância a decisão caiu, mas várias ordens de censura se mantiveram

2 -Em maio, na cidade cearense de Juazeiro do Norte, três pessoas sequestraram e torturaram Gilvan Luiz, Pereira, editor do semanário "Sem Nome". Ele faz cobertura crítica da prefeitura e foi libertado pela policia. Até agora não se sabe quem ordenou o crime, de acordo com o CPJ (Comitê para Proteção de Jornalistas).

3- O CPJ aponta também a vulnerabilidade de jornalistas do interior do pais em seu trabalho. Francisco Gomes de Medeiros, diretor de jornalismo da Radio Caicó, no Rio Grande do Norte, foi assassinado a tiros em outubro supostamente por uma cobertura criminal realizada pelo jornalista

PRIESTER, D.R; HELLER, B.: 'Pra Frente, Brasil!' E 'Je Vous Salue, Marie' : Dois Casos De Censura Cinematográfica Em Tempos De Redemocratização (1982 E 1986) 
em 2007. Um promotor, no entanto, indicou que o mandante do crime pode ter sido outro alvo de reportagens do jornalista.

4 - "Numa investigação conbecida como "Operação Faktor", a Policia Federal brasileira gravou centenas de horas de conversas telefônicas nas quais Fernando Sarney, filho do presidente do Senado, discutia negócios e assuntos legislativos. $O$ Estado publicou reportagens tendo como base as transcricones vazadas de mais de 300 horas de conversas do filho de Sarney, alvo de uma investigação federal em andamento. "O inquérito revelou o senador e familiares próximos negociando empregos e benefícios como se o Senado fosse uma empresa privada", disse Marcelo Beraba, um dos principais editores do Estadão. E o jornal estava apenas começando a contar a história.

5 - Em 31 de julho de 2009, porém, a familia Sarney convenceu o juiz. Dácio Vieira a conceder uma liminar proibindo o jornal de cobrir qualquer aspecto da investigação. Vieira determinou que o jornal fosse multado em 150 mil reais para cada reportagem publicada sobre o caso, e estendeu a proibição a qualquer outro veículo que reproduzisse os artigos do Estadão. O juiz. concedeu a liminar um dia depois de o pedido ser feito por Sarney e sem que houvesse nenhuma audiência. Diferentemente da maioria dos assuntos civis, não houve ação subjacente, como queixa por difamação; a familia Sarney queria apenas proibir a publicação. O jornal recorreu da decisão ao Supremo Tribunal Federal (STF), a mais alta corte do Brasil, e continua documentando o caso Sarney, na esperança de um dia divulgar os resultados. $A$ decisão do STF só deverá sair em meados de 2011. In: bttp:/ / noticias.oul.com.br/politica/2011/0

2/16/ataques-a-imprensa-atingiram-maiornivel-mundial-em-14-anos-dirjornalista.jhtm. Acesso:12/05/ 2011]

Jornais, revistas, televisão, rádio.... praticamente todos meios de comunicação são controlados. Notícias são censuradas, jornalistas reprimidos, tudo a fim de manter a população apenas informada do que interessa, daquilo que não possibilite uma alteração de pensamentos. Então, são criados programas televisivos para manter a população ocupada, mantê-los "pensando" Os meios de comunicação estão se focando em "queimar" o tempo das pessoas, tornando, assim, a manipulação mais fácil e indireta.

$\mathrm{Na}$ peça teatral "Fahrenheit 451", com direção de Fernando Nitsch, apresentada e janeiro de 2011, pelo grupo do teatro Célia Helena, é possível ver claramente isso. A peça se passa em uma sociedade futurista, onde livros são proibidos e queimados, a programação da televisão se baseia em puro entretenimento e as pessoas têm pelo menos três televisores na mesma sala, tudo para não perder "nada". As pessoas têm medo dos livros, tem medo de pensar diferente porque, caso isso acontecesse, eram reprimidas pelos bombeiros, que já não tinham mais o trabalho de apagar o fogo e, sim, de queimar

2 Texto escrito por Ray Bradbury em 1953, com adaptação cinematográfica dirigida por François Truffaut em 1966. 
livros e reprimir a população subversiva. Encontra-se também diversas notícias manipuladas/selecionadas nos meios de comunicação indoor ${ }^{3}$ (Midia Indoor ou Mídia Interna). Exemplos podem ser facilmente vistos em elevadores, filas, recepções, ônibus e muitos outros estabelecimentos fechados. Notícias sem utilidade batem o recorde de exibição. Tudo a fim de manter a população "informada".

3 Midia Indoor é todo e qualquer tipo de propaganda ou divulgação feita dentro de qualquer estabelecimento, especialmente em locais de espera forçada como: filas, recepções, elevadores, ônibus entre outros. [In: www.wikipedia.org]

8 PRIESTER, D.R; HELLER, B. : 'Pra Frente, Brasil!' E 'Je Vous Salue, Marie' : Dois Casos De Censura Cinematográfica Em Tempos De Redemocratização (1982 E 1986) 


\section{Pra frente, Brasil}

O filme "Pra frente, Brasil" teve uma história complicada no processo de censura, conforme atestam os documentos extraídos do site www.memoriacinebr.com.br. o filme fora censurado com argumentos indevidos, mas segundo os censores estavam na lei, porém não se enquadravam na situação.

Advogados tiveram de ser contratados pois

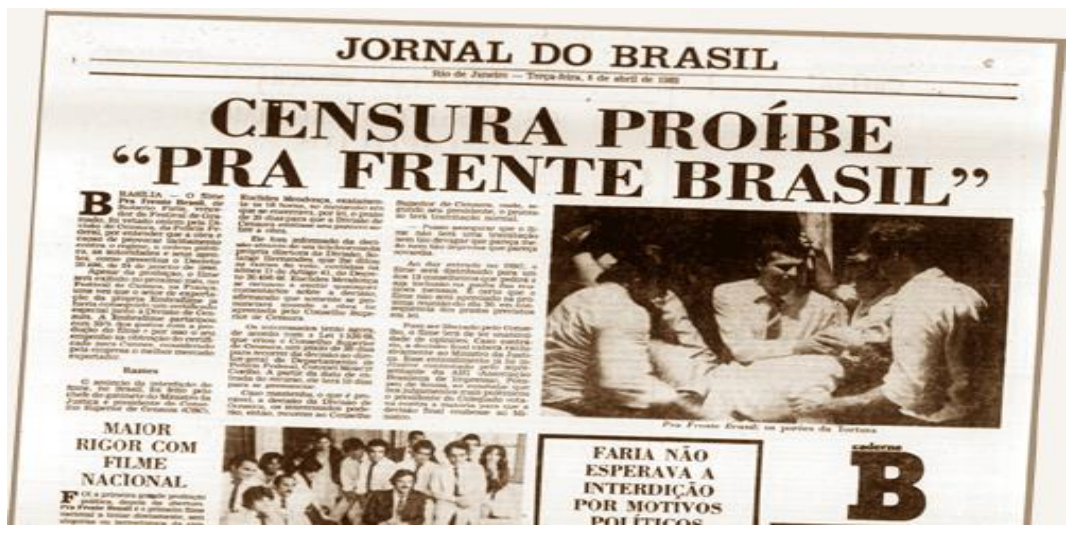

[In: www.google.com]

Em 3 de março de 1982, "Pra frente, Brasil" foi convidado a participar do XXV Festival Internacional do Filme de Cannes. Ocorreu, então, o primeiro pedido de autorização para exibição, concedida em 8 de março do mesmo ano, pela técnica de censura, Maria Luiza Lopes Rezende. Já em 18 de março, o filme é liberado com classificação etária de 18 anos, pelo técnico de censura, Manuel Adam Valente. E em 22 de março, a também técnica, Selia Natalha Stolte Rouver autoriza, com os mesmos argumentos, a exibição do filme. Porém, em 5 de abril o filme é censurado pela Divisão de Censura de Diversões Públicas e tem sua exibição proibida, com base no art. 41, letra D, do Decreto n. 20.493/46, incluso no
"Art.41. Será negada a autorização sempre que a representação, exibição ou transmissão radiotelefônica:...d) for capaz de provocar incitamento contra o regime vigente, a ordem pública, as autoridades e seus agentes;...”. [In: www.memoriacinebr.com.br.]

Em carta enviada em 4 de maio, para o Diretor Geral do Departamento de Polícia Federal, a Eletro Filmes diz que o filme não se enquadra no artigo citado e pede deferimento.

"Em nenbum momento a obra cinematográfica incita ou pretende incitar a coletividade contra as autoridades constituidas ou o regime vigente. Muito ao 
contrário, o filme consagra o respeito à autoridade constituida, como sendo a única à qual deveriam ser atribuidas as tarefas de proteção da segurança coletiva."

Resposta que foi dada somente 10 dias depois do pedido de deferimento, pela famigerada Solange Maria Teixeira Hernandes, a musa da censura. A saída de Solange Maria Teixeira Hernandez da direção da censura, mulher que vetou pessoalmente incontáveis obras, marcava novos tempos. Solange, que deixou em março o cargo em que permaneceu por três anos, tinha fama de centralizadora e, diziase, chegava a interferir diretamente no conteúdo de diversos jornais com telefonemas pessoais para as chefias de redação.

Ela chegara a vetar, em decisões polêmicas, obras que tinham parecer favorável do conselho de censura, como fez com o filme "Pra frente Brasil", de Roberto Farias. "Ela, inclusive, fraudou esse processo', declarou na época o jornalista Pompeu de Souza, representante da Associação Brasileira de Imprensa no Conselho Superior de Censura." (BARREIROS, Edmundo e SÓ, Pedro, 1985).

Solange envia uma carta para anunciar a não liberação do filme. Em protocolo interno ela comunica com as seguintes palavras:
'I- Por delegação do Sr. Diretor-Geral do DPF e com fulcro nos mesmos preceitos legais que embasaram o despacho de fls. 21, decido pela não liberação do filme "Pra frente, Brasil”. II- Comunicar interessado." [In: www.memoriacinebr.com.br]

Como se pode constatar, ela não se embasa em nenhum argumento legal, ou muito menos se justifica. A carta enviada ao "interessado" segue os mesmos parâmetros, sem justificativa, sem argumento, simplesmente diz:

"Comunicamos a V.Sa. que seu pedido
protocolado sob n. 3999/82-DCDP,
referente ao filme "Pra frente, Brasil", foi
indeferido, mantendoportanto, o veto imposto
anteriormente pela DCDP" [In:
www.memoriacinebr.com.br].

Em 15 de maio de 1982, Produções Cinematográficas R.F. Farias LTDA., faz uma procuração para que os advogados, Manuel Alceu Affonso Ferreira e Maurício Branda Lacerda possam "praticar todos e quaisquer atos que se fizerem necessários ao integral desempenho do mandato ora outorgado".

Manuel Alceu abre um recurso contra a recusa na liberação do filme. O documento tem 17 páginas e consta de argumentos muito concretos, inclusive dizendo que a Diretoria da Divisão de Censura sofre um vício de procedimento. 
Manuel se baseia em um fato muito concreto e lógico, que praticamente anula a censura do filme por si próprio:

"7 - Como sabido, 'Pra frente, Brasil' foi realizado em regime de co-produção com a Empresa Brasileira de Filmes S. $A$ EMBRAFILME', sociedade de economia mista que, vinculada ao Ministério da educação e Cultura, para isso está autorizada [...]Dessa produção conjunta da fita, provém irretorquivel consequência jurídica: o regime de isenção censória, no caso ignorado.8.- Realmente. A prevalecer a incidência, na hipótese sub studio, dos cânones do Regulamento do Serviço de Censura de Diversões Públicas' (aprovado pelo decreto n. 20.493, de 24 de janeiro de 1946), há de por igual predominar a norma traçada no parágrafo único de seu artigo 5. Ficam isentos de censura os filmes produzidos pelo Instituto Nacional do Cinema Educativo do Ministério da Educação e Saúde e demais órgãos oficiais.' [...]Enquanto sociedade de economia mista ligada ao Ministério da Educação e Cultura [...], a EMBRAFILME integra a Administração Federal Indireta $[\ldots]$ É, portanto, 'órgão oficial'. [...] Assim sendo, Pra frente, Brasil' é um filme produzido por órgão oficial, e, sob essa credencial, imune à fiscalização censória (Dec. n.20.493, art. 5).[...]" [FERREIRA, Manuel Alceu Affonso. In:www.memoriacinebr.com.br.]

Em outras palavras, admitir-se que os filmes produzidos pela EMBRAFILME possam receber veto exibitório total como aqui se passou, "conduz a situação incoerente com a 'lógica do razoável' que o Direito resguarda: o Estado realiza o filme, e ele próprio o proíbe..."

Manuel Alceu, como se pode ver, soube muito bem como colocar seus argumentos em pauta, mas ele foi além, disse que o veto constituiu em "ato administrativo ilícito".

Ele se refere também ao artigo que foi utilizado para proibição do filme (Artigo 41 do Decreto n. 20.493). “[...] estava aludindo à disciplina censória do teatro e de outras expressões artísticas, sem englobar cinema, tudo como deflui do rol transcrito no artigo 40 daquele decreto [...]. Aliás, mesmo quando diligenciou alargar esse tratamento censório a outros espetáculos públicos, o Decreto n. 20.493 apontaria "as exibições de espécimes teratológicos" e "as apresentações de préstitos, grupos, cordões, ranchos, etc. (sic), e estandartes carnavalescos", propositadamente não incluindo as projeções cinematográficas.

[...]" "A verdade, Egrégio Conselho, é que a interdição de 'Pra frente, Brasil' encontraria apoio no preceito invocado somente se o 'regime vigente', a 'ordem politica' on as 'autoridades constituidas' pudessem ser confundidos, em indesculpável baralbamento, com aqueles que, às escondidas, transmudam-se em agentes da lei, assumindo funções e exercendo atividades que a ordem juridica jamais thes outorgou. Ai sim, e somente aí, caberia a interdição decretada. [...]. Porquanto assim não é, 'Pra frente, Brasil' defende o 'regime vigente' www. fics. edu. br 11 
, advoga a 'ordem pública' e, acima de tudo, lança-se à radical defesa auctoritas legalmente reconbecida." [FERREIRA, Manuel Alceu Affonso. In: www.memoriacinebr.com.br.]

Alceu termina o recurso com a seguinte frase:

"[...] espera-se o provimento do recurso para, em se reformando as decisões inferiores, liberar-se, sem cortes ou restrições, o filme interditado." FERREIRA, Manuel Alcen Affonso. In: www.memoriacinebr.com.br].

Solange devolve o documento para Alceu dizendo que o recurso "deve ser dirigido diretamente aquele Colegiado, não havendo necessidade de ser encaminhado através do Senhor Diretor-Geral do Departamento de Polícia Federal." Daniel da Silva Rocha, relator, faz um relatório autorizando o filme a ser exibido. "Sou de parecer que o filme pode ser liberado para maiores de 18 anos".

Porém, em 25 de agosto de 1982, Pedro Paulo Wandeck de Leoni Ramos, conselheiro, sugere que seja adiada a decisão.

\footnotetext{
"Sugiro, portanto, aos meus nobres companheiros, que o filme seja retirado de pauta e devolvido ao produtor, outorgando-sethe o direito de apresenta-lo a novo julgamento em janeiro de 1983, quando fatalmente serão outras as condições de absorção." [n: www.memoriacinebr.com.br].
}

Em 26 de agosto houve uma reunião do Conselho Superior de Censura e, no decorrer dos fatos, o presidente concede a palavra ao Dr. Pompeu de Souza, que havia pedido a analise do filme "Pra frente, Brasil", mas verificaram que 4 pareceres de técnicos de censura haviam sido visivelmente retirados do processo. Como o conselho não possui atribuições administrativas pede ao Senhor Ministro que verifique a irregularidade. Há indícios que Solange Hernandez tenha tirado os pareceres, mas Pompeu diz "que não esperava que ela admitisse que tirara as peças do processo”. Então, “já que o processo havia baixado em diligência; este lê seu parecer propondo a retirada de pauta do filme, com a condição de ser apreciado em janeiro próximo, quando as condições já serão outras, solução louvada pelos seus pares $[\ldots] "$.

Em 14 de dezembro de 1982, houve uma reunião do Conselho Superior de Censura e, no dia 22, foi emitido o Certificado de Censura, que concedia a autorização para exibição do filme, a única censura feita foi que o filme só poderia ser exibido para maiores de 18 anos, devido às cenas de violência.

Como condição de liberação, deveria ser inserido o seguinte letreiro no início do filme: 


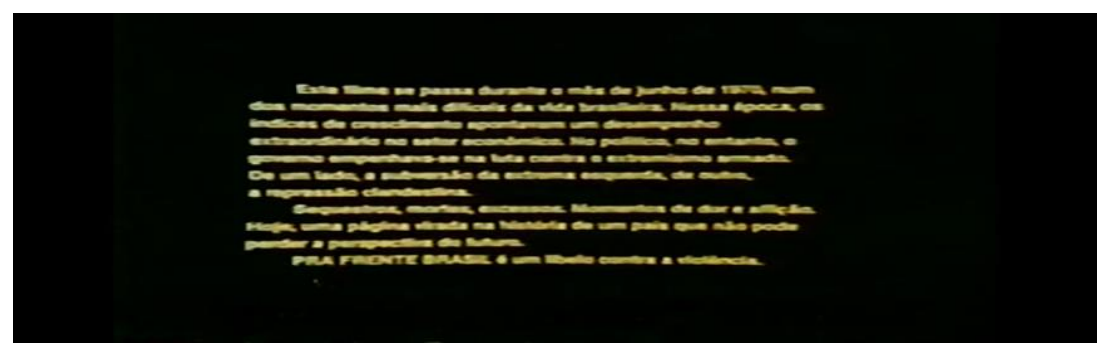

Este filme se passa durante o mês de apresentação, em rádio e televisão, de espetáculos proibidos para os menores de: I - dez anos, até 20b; II - quatorze anos, até 22b; III - dezoito anos, em qualquer borário".

desempenho extraordinário no setor econômico. No politico, no entanto, o governo empenhava-se na luta com o extremismo armado. De um lado, a subversão da extrema esquerda, de outro, a repressão clandestina. Sequestros, motes, excessos. Momentos de dor e aflição. Hoje, uma página virada na história de um país que não pode perder a perspectiva do futuro.Pra frente, Brasil é um libelo contra a violência.

Em 28 de maio de 1985, o Departamento de Polícia Federal sugere, no parecer 2977/85, que o filme seja exibido somente após às 22 horas e que os palavrões "porra" e "filho da puta" fossem suprimidos. No dia 29 de maio, no parecer 2978/85, o mesmo departamento sugere a exibição do filme apenas para depois de 23 horas. Já no dia 30, no parecer 2979/85, o departamento informa que:

"infelizmente, não há espaço para a sua exibição na TV, em respeito ao que dispõe a Lei 6.697/79, novo Código de Menores, em seu art. 53 item III, in verbis: "Art. 53 - Será vedada a

Porém, o novo diretor do DCDP, Coriolano Loiola Cabral Fagundes, sucessor do cargo de Solange, concede a autorização, em 31 de maio, do filme para televisão, conforme o parecer 2977/85. Em 11 de julho de 1985, a Produções Cinematográficas R.F. Farias LTDA., pede o reexame da versão para televisão, com os palavrões omitidos, e aproveita a oportunidade para pedir "que a classificação etária seja reduzida para 21 horas”. E, em 25 de julho, Coriolano de Loiola Cabral Fagundes, manda carta ao Ministro de Estado da Justiça:

"Em atenção à orientação de V. Exa. em proporcionar condições favoráveis ao florescimento de uma indústria cinematográfica de alto nível técnicoartístico, tenho a satisfação de submeter a sua apreciação a solicitação de Produções Cinematográficas R.F. Farias Ltda, no sentido do filme "PRA FRENTE BRASIL" ser liberado para após às 21 (vinte e uma horas, em televisão conforme o pedido 
anexo." Dia 29, Fernando Lyra, Ministro da Justiça, opta pela “decisão, para liberar o filme "Pra frente Brasil", de Roberto Farias, com a classificação horária de 21 (vinte e uma) horas, em televisão"

O Certificado saiu no dia 3 de setembro de 1985, e como é possível ver, a censura estava muito mais flexível, e em 15 de junho de 1988, com a nova constituição, o Certificado de Censura final é emitido, sem qualquer tipo de censura, e como única condição a inserção do mesmo letreiro referido anteriormente.

\section{Críticas foram feitas no filme, que somente após longa análise foi possível somente após longa análise foi possivel}

verificar. Fatos como o adesivo "Brasil, ameo ou deixe-o" que pode ser visto colado em um carro utilizado pelo irmão de Jofre para fugir. Ou que Jofre é sequestrado no dia do primeiro jogo da Copa do mundo e, consequentemente, morre no dia do último jogo. Fato esse que criticou o controle que existiu nos meios de comunicação, mostrando como a Copa foi utilizada para minimizar a atenção da sociedade brasileira para a outra disputa, que ocorreu na mesma época.

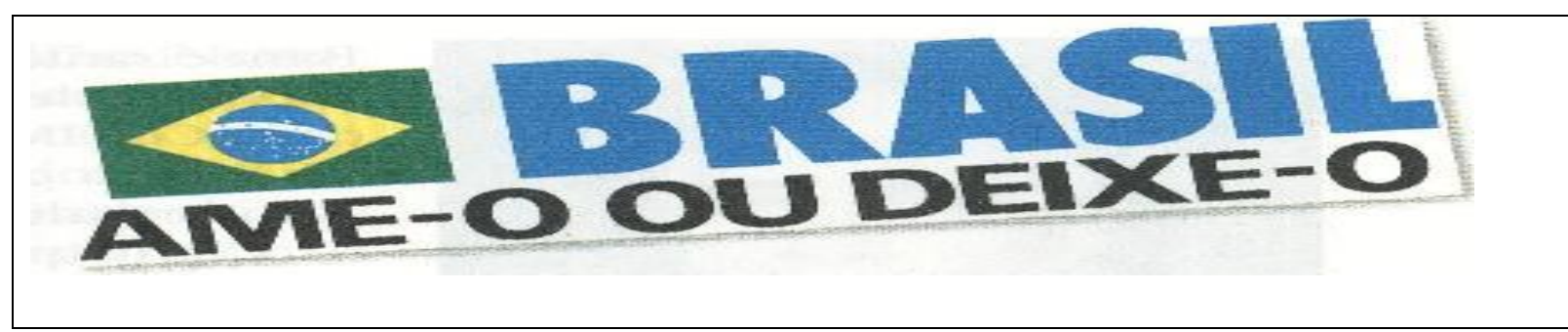

Os protagonistas foram baseados em pessoas ou em fatos reais. Dr. Barreto é inspirado em Sérgio Paranhos Fleury, que utilizava o codinome "Valentim Barreto". Dr. Geraldo Braulen em Henning Albert Boilesen, diretor do grupo Ultra, que foi assassinado por militantes do MRT (Movimento Revolucionário Tiradentes) e da ALN (Ação Libertadora Nacional). A circunstância envolvendo a morte de Resende é real, foi retratada no livro "O que é Isso, Companheiro", de Fernando Gabeira. Houve um guerrilheiro chamado
Zé Roberto, que realmente foi morto em um combate contra as forças da repressão. O americano que leciona a palestra de tortura é evidentemente, Dan Mitrione, O Mestre da Tortura, que ensinou, na prática, às forças policiais brasileiras a torturar presos políticos (utilizando como cobaia presos, mendigos e indigentes). Mitrione foi morto em julho de 1970, no Uruguai, pelo grupo esquerdista Tupamaros. Essas aulas de tortura realmente aconteceram no Rio de Janeiro, em fins de 1968 ou início de 1969, tendo sido 
denunciadas pelo prisioneiro político Murilo Pezutti, que serviu de cobaia em uma delas.

Exemplos como esses podem ser encontrados durante toda história do Brasil, principalmente durante as eleições, quando aparentemente os problemas desaparecem, mas não podemos nos deixar enganar, eles existem, só estão sendo disfarçados com o verniz efusivo utilizado durante os períodos de grandes mudanças.

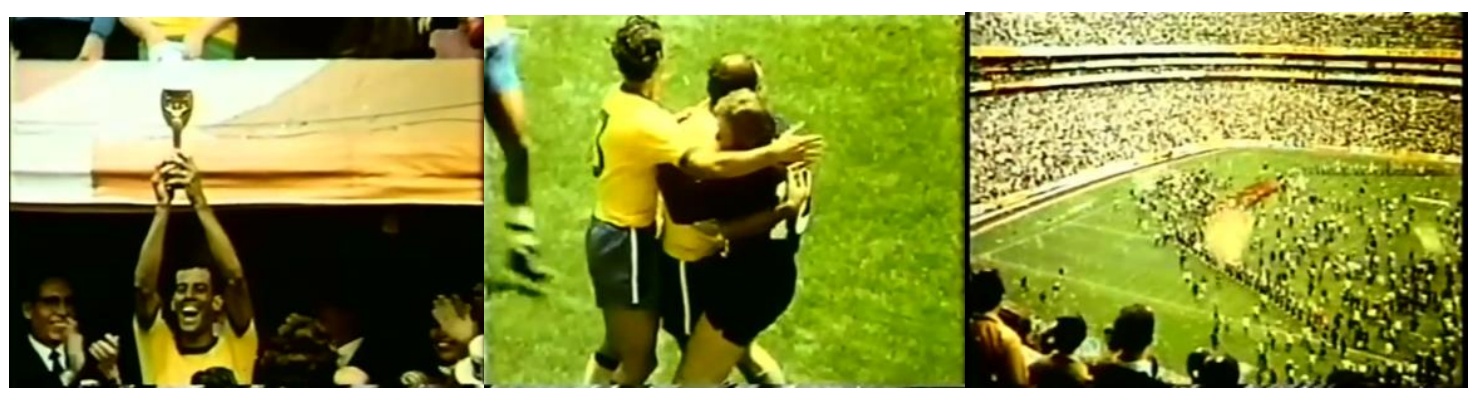

[In: "Pra frente, Brasil" de Roberto Farias, 1982].

\section{Je vous salue, Marie}

Mas a censura vai além das questões políticas como é o exemplo do filme "Je vous salue, Marie", filme que trata da questão religiosa, mas de forma implícita, dificultando seu entendimento para quem não sabe do que se trata. Godard, um grande diretor, teve uma idéia um tanto quanto inovadora: como seria representada a história do nascimento de Jesus nos dias de hoje? Pergunta que é respondida no filme "Je vous salue, Marie", que não é nada além da história do nascimento do menino Jesus, porém com ênfase na mãe, Maria. Podemos dizer que a história foi reconstruída, quando vemos exemplos de extrema modernização na história, como o Anjo Gabriel chegando à terra de avião e pegando um táxi para chegar até Maria.

Um ponto de vista interessante, pois chega a ser estranho, nos dias de hoje, pensar que uma mulher, virgem, inocente e simples recebe a mensagem por um homem chamado Gabriel de que ficou grávida e dizendo que é uma obra divina. Quem era aquele homem? Obra divina? Grávida? Essa história de obra divina parece uma coisa que está anos luz distante de nós, é o tipo de coisa que nunca imaginaríamos que pudesse nos acontecer, chega a ser surreal pensar nos fatos apresentados pelo filme.

Joseph, ou José, é uma vítima desses acontecimentos, pois vê sua noiva, Maria, grávida, sem nunca tê-la tocado. Confuso para ele, rapaz jovem e moderno que era. Era difícil compreender a espiritualidade da trama, era como se ele fosse "corno", pois, praticamente, era impossível ela estar grávida sem ele nunca tê-la tocado, então, de acordo com a lógica, alguém havia-o feito. Isso era o que ele pensava. Porém com o decorrer do tempo, brigas e crises, e por bem ou por mal, José acabara entendendo a história. 
O filme foi muito criticado por mostrar uma intimidade de Maria nunca explorada antes, uma intimidade feminina, uma intimidade humana de Maria como mulher, confusa com todas as mudanças. Nada obsceno, nada que não vemos hoje, mas foi inovador, foi um ângulo diferente para abordagem da história toda. Há cenas em que Maria fica nua, porém não é um nu vulgar, é um nu artístico, com propósito. Godard teve cuidado em filmar Maria, inclusive quando ela vai ao ginecologista. Cena que rendeu inúmeras críticas, chegando ao ponto de ser considerado sacrilégio o fato de o médico tê-la tocado.



Uma história acontece em paralelo à trama principal. Uma aluna, Eva, que mantém relações sexuais com um professor. A principio parece não ter relação com a história principal, mas pode-se perceber um contraponto com a situação de Maria, que sofridamente oprime seus desejos de jovem mulher, não permitindo que Joseph sequer a toque.

As relações feitas por Godard podem ser facilmente percebidas, por exemplo, quando dá o nome de Eva para a aluna e, principalmente, quando, seduzindo seu professor, oferece-lhe uma maçã. Signo que torna a cena extremamente simbólica, pois a maça é o fruto do pecado. Paradoxo muito bem colocado por Godard.

A simplicidade com que Maria e José são representados na obra mostra exatamente a simplicidade que tinham os pais de Jesus nos tempos de Herodes. A história toda se passa em uma cidade grande, diferente do campo primitivo da história bíblica, uma cidade alheia aos mistérios da fé. Godard atualiza os personagens com os conflitos de casais contemporâneos: José 
tem uma amante e Maria duvida de seu amor.

A cena final é de uma genialidade ímpar, quando Maria, após ter colocado o menino no mundo, e ele seguido seu caminho, pega um batom vermelho e, em close, pinta os lábios. Um signo brilhante, que nos mostra a liberdade que Maria irá desfrutar após ter cumprido sua missão.

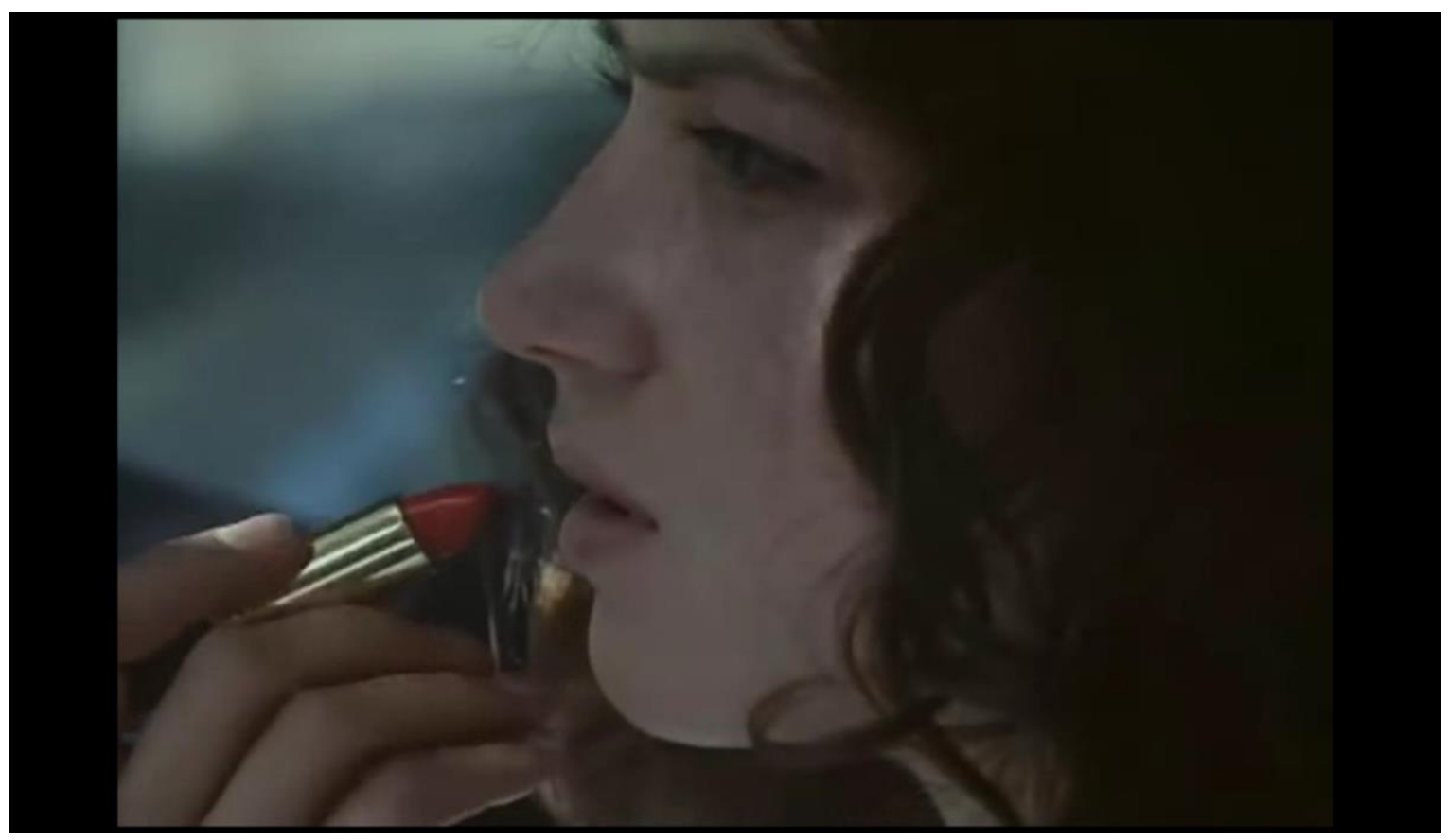

A censura do filme foi uma questão ética e religiosa, devido às cenas que continham uma intimidade excessiva de Maria, ou pela cena em que o ginecologista a toca. Exageros, pois se trata de arte e, em momento algum, Maria foi representada de forma vulgar.

\section{Considerações finais}

Com os exemplos dos filmes citados anteriormente, podemos ver como a censura atuou no final da ditadura. Imparcial e acima da lei tomou conta de toda informação publicada na época, onde a população não tinha nem o direito de defender uma idéia, ou muito menos de tê-la. A repressão ocorria de forma indevida e desumana. Cenas em "Pra Frente Brasil" mostram como eram tratados os presos por subversão. E por "tratados" entenda "torturados".

É um cenário muito difícil de conviver, ainda mais para os artistas, que tinham sempre que resguardar sua arte, tendo que utilizar de ferramentas para não serem identificados/censurados, como codinomes, analogias, metáforas, referencias 
e outras. Mas não se pode dizer que foi o fim da censura quando Coriolano Fagundes disse que a palavra "censura" seria proibida, assim que sucedeu o cargo de Solange. Ou mesmo quando a lei da Anistia, pelo presidente Figueiredo, onde o Brasil deixaria de lado o regime autoritário e então reintegraria à sociedade aqueles exilados, que por motivos políticos fugiram ou foram perseguidos no país desde 1964.

A censura, atualmente, é aplicada com tanta frequência que não sabemos mais o que realmente se passa, nos dando a ilusão de que sabemos tudo, quando na verdade o "tudo" que sabemos é o que querem que saibamos.

"Fica claro, portanto a grande intenção da Indústria Cultural: obscurecer a percepção de todas as pessoas, principalmente, daqueles que são formadores de opinião. Ela é a própria ideologia. Os valores passam a ser regidos por ela. Até mesmo a felicidade do individuo é influenciada e condicionada por essa cultura." (Adorno).

\section{Referências}

BARREIROS, Edmundo e SÓ, Pedro. 1985, o ano em que o Brasil recomeçou. Rio de Janeiro: Ediouro, 2005.

STEPHANOU, Alexandre Ayub. Censura no regime militar e militarização das artes. Porto Alegre: EDIPUCRS, s.d.

\section{Referências Eletrônicas}

http://www.memoriacinebr.com.br http://noticias.oul.com.br/politica/2011/02 /16/ataques-a-imprensa-atingiram-maiornivel-mundial-em-14-anos-dizjornalista.jhtm] http://jus.uol.com.br/revista/texto/11630/ a-inconstitucionalidade-do-novo-artigo-478do-cpp. 
OR.SUCEX/O/4/82 Rio de Janeiro, 03 de março de 1982

\author{
Senhor chefe,
}

Muito agradeceria os bons ofícios de Vossa Senhoria no sentido de conceder autorização especial para que o filme "Pra Frente Brasil", dirigido por Roberto Farias, que foi convidado pela Comissão de Seleção do XxV Festival Internacional do P1lme de Cannes, possa ser visionado pelo Senhor Gilles Jacob,De legado-Geral daquele evento cinematográfico, conforme côpia de correspondência anexa.

\title{
a da $\mathrm{C}_{\mathrm{e}}$
}

Aproveito \& 8 \%ortypidade parfa renovar a Vossa senho ria protestos de considéraçã e apreço.



superintendente de Comerciấl $\mathrm{z}$ ação

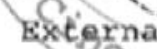

Qma BIa

Ilustrissimo Senhor

Dr. Hel1o Guerrueiro

M D Chefe do Serviço de Censura e

D1versões püblicas

Av. Rodrigues Alves no 138 andar

Rio de Janeiro - R J

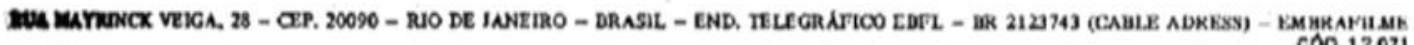


aningO DR CERSURA DE DIVERSOES PUBHICAS SR/RJ

\section{AUTORIZAQRO BSPEYIAL}

a prosonto autor:zagño ospocial subst1tu1 o Cort1roodo do Consura, rolativo so pilino "PFA FRERTE BRASIL", dirigido

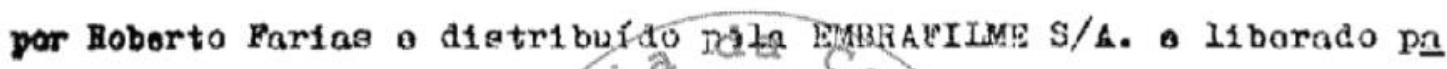
ra o IXV Postival Intornfoitonal do Filmos da Cannes.

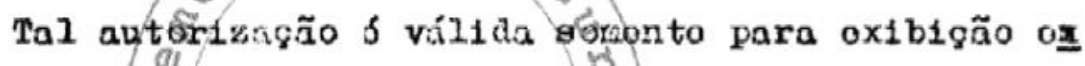
olne1va no XXXV Foetivalintornacional do Filpo do Cannos. F10 do Janotro, 8 da nimgo da 1982
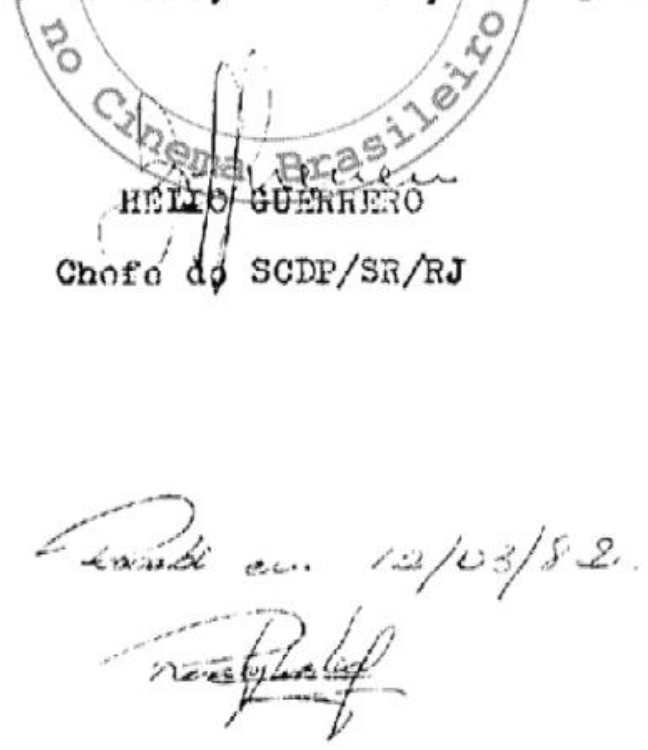


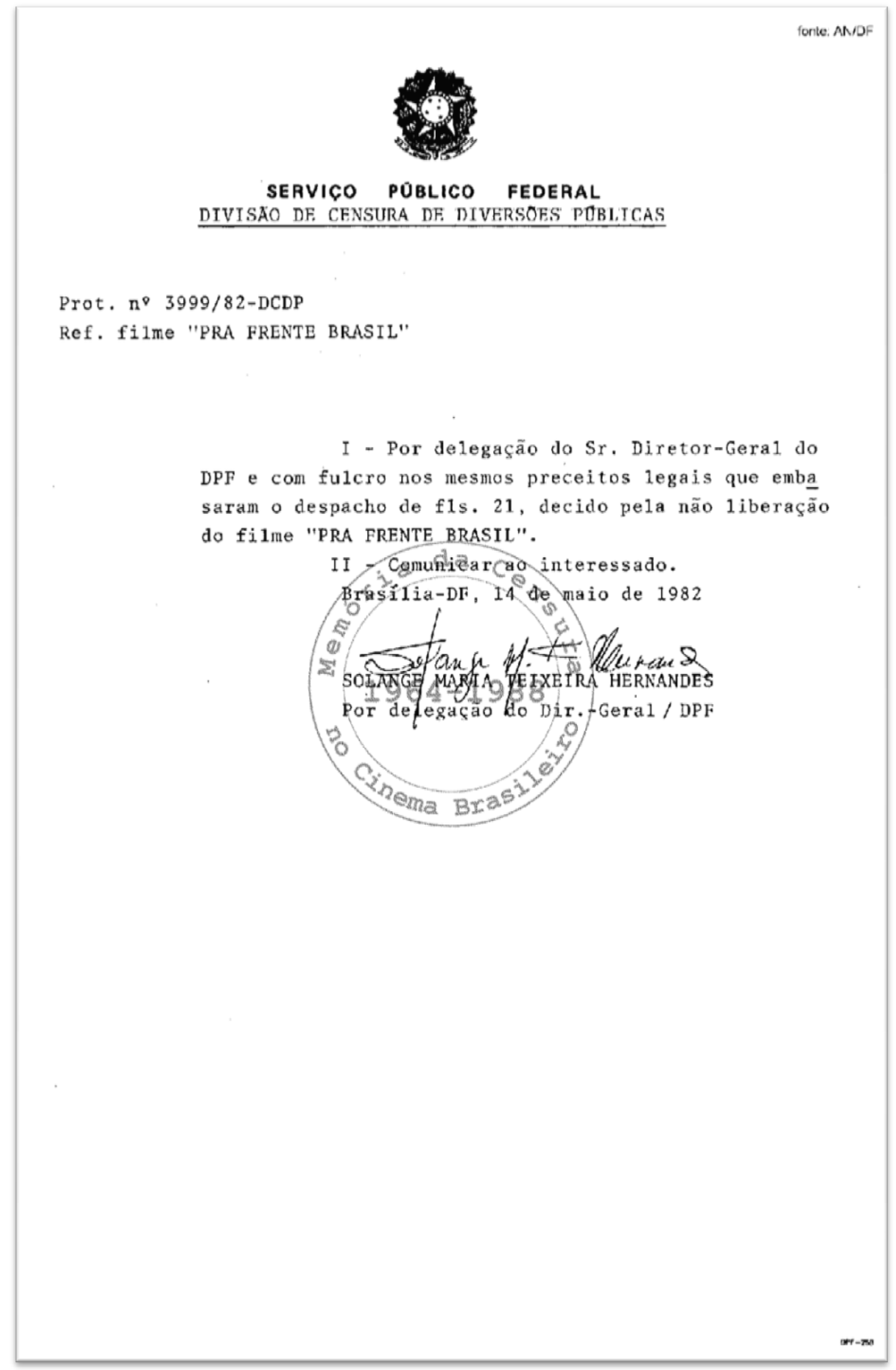




\section{CERTIFICADO DE CENSURA}
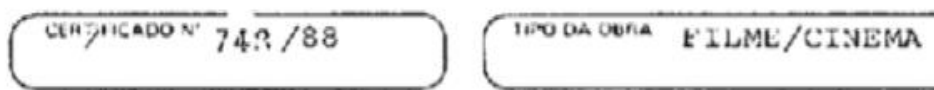

mants: /COLORIDO

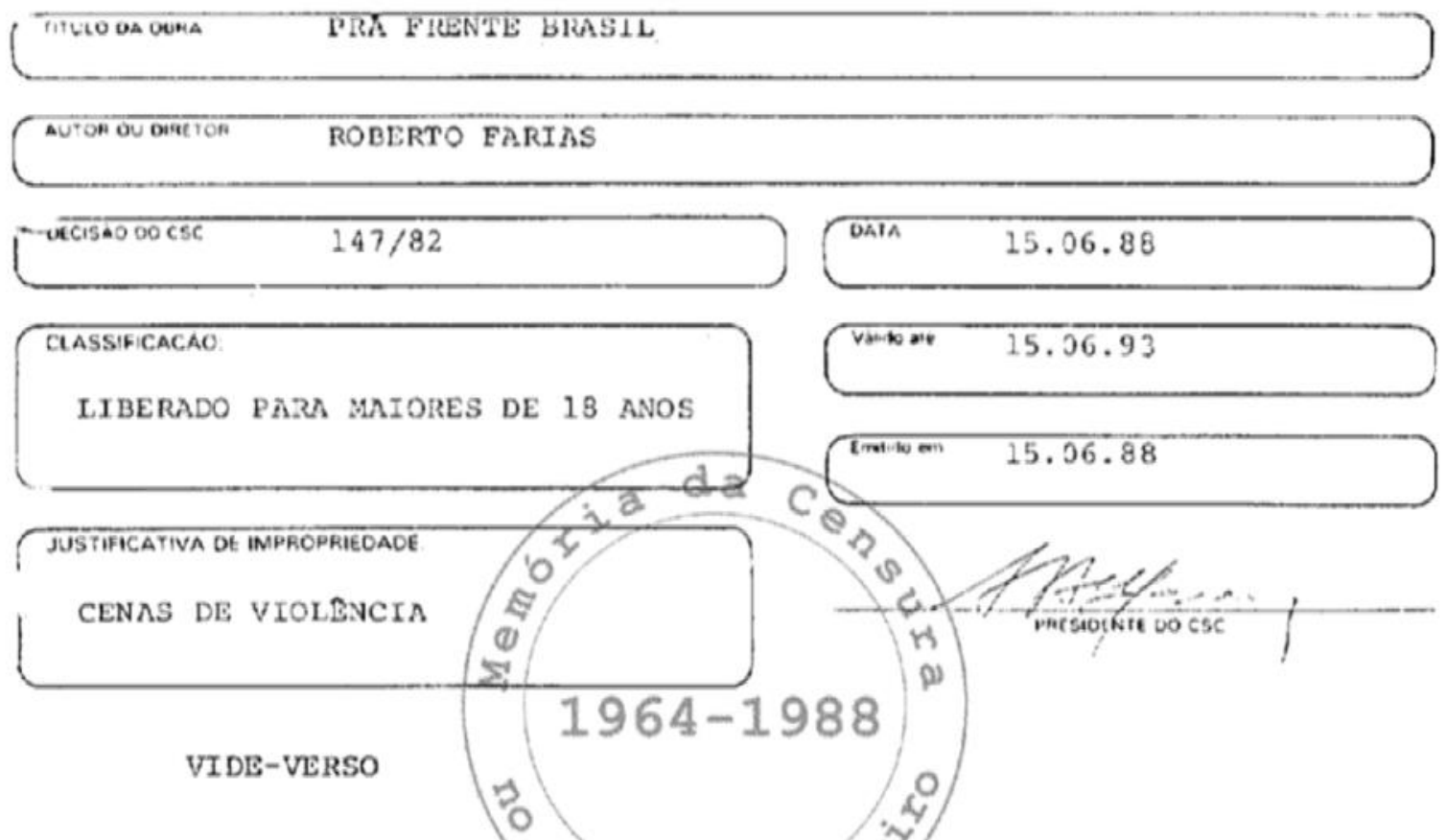

Certifico que, por Deciš̌o do Consattio Superior de Censura, edoloda na reuniso plenaria abaixo indicade, fo liberada, com a classificaçðo constante do versQ. Japeguinte-obra

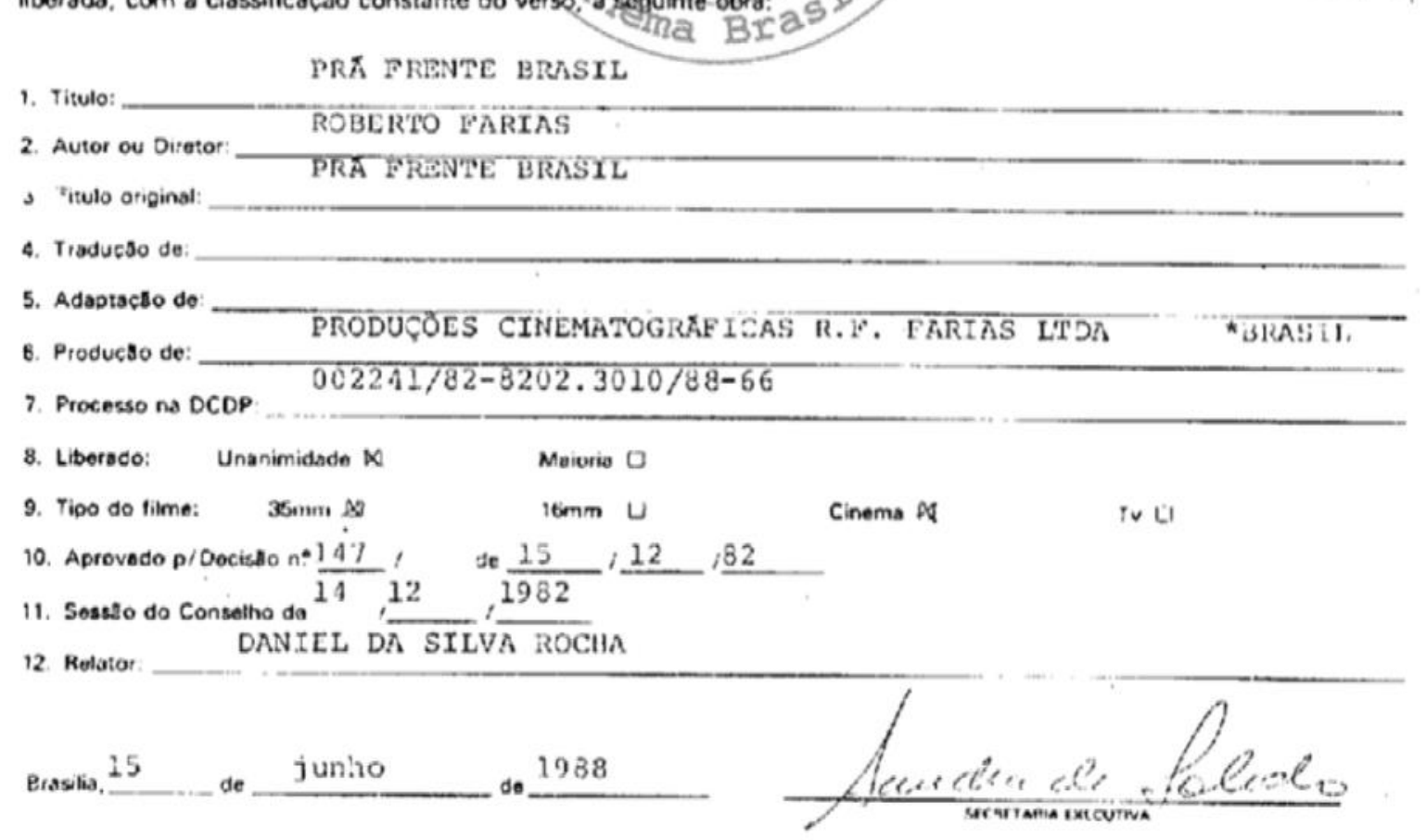




\section{CONSELHO SUPERTOR DE CFNSURA}

INDISPENSAVEL INSERÇÃO DE LETRETRO ROTATIVO NO INICIO DA PELICULA INTITULADA "PRA FRENTE BRASIL", CONFOR ME CLETIFICADO DE CENSURA NQ 393/88-CSC, QUE E A SEGUINTE:

\section{$\underline{I N S E R C \tilde{O} O}$}

\section{LETREIRO ROTATIVO}

ESTE FILME SE PASSA DURANTE O MES DE JULIIO DE 1970, NUM DOS MOMENTOS MAIS DIFICEIS DA VIDA BRASILEIRA. NESSA EPOCA, OS INDICES DE CRESCIMENTP APONTAVAM UM DESEMPENIIO EXTRA* ORDINARTO NO SETOR ECONOMIEO. NO POLTTJCO, NO ENTANTO, O GOVER NO EMPENHAVA-SE NA LUTA'OCONTRA O EXTREMPSMO ARMADO. DE UM LADO, A SUBVERSÃO DA EXTREMAY ESQUERDA, DE OUTROMA REPRESSÄO CLANDESTI NA.

SERUESTRÓS, MORTES, EXCESSOS. MOMENTOS DE DOR E AFLIÇת̆O HOJE, UMA RKGINA VIRADA NA HISYORIA DE UM TAIS QUE. NÑO PODE PERDER PERSPECTIVA QO FUTURO.

CI $\Lambda$.

PRA FRENTR BRASIIg, E' UM LIBELO CONTRA A VIOLFN


Gécretăria-Exocutiva

$$
\text { C.S.C. }
$$

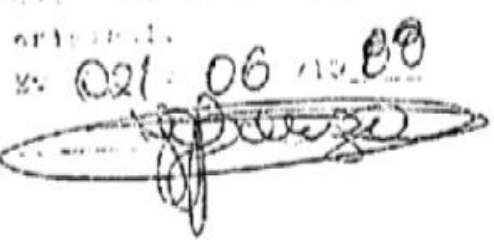

$\mathrm{ecg} / \ldots$ 